\title{
On determining the noon polar cap boundary from SuperDARN HF radar backscatter characteristics
}

\author{
M. Pinnock, A. S. Rodger \\ British Antarctic Survey, Madingley Road, Cambridge CB3 0ET, UK \\ Received: 10 March 2000 / Revised: 18 September 2000 / Accepted: 28 September 2000
}

\begin{abstract}
Previous work has shown that ionospheric HF radar backscatter in the noon sector can be used to locate the footprint of the magnetospheric cusp particle precipitation. This has enabled the radar data to be used as a proxy for the location of the polar cap boundary, and hence measure the flow of plasma across it to derive the reconnection electric field in the ionosphere. This work used only single radar data sets with a field of view limited to $\sim 2 \mathrm{~h}$ of local time. In this case study using four of the SuperDARN radars, we examine the boundary determined over $6 \mathrm{~h}$ of magnetic local time around the noon sector and its relationship to the convection pattern. The variation with longitude of the latitude of the radar scatter with cusp characteristics shows a bay-like feature. It is shown that this feature is shaped by the variation with longitude of the poleward flow component of the ionospheric plasma and may be understood in terms of cusp ion time-of-flight effects. Using this interpretation, we derive the time-of-flight of the cusp ions and find that it is consistent with approximately $1 \mathrm{keV}$ ions injected from a subsolar reconnection site. A method for deriving a more accurate estimate of the location of the open-closed field line boundary from HF radar data is described.
\end{abstract}

Key words: Ionosphere (ionosphere-magnetosphere interactions; plasma convection) - Magnetospheric physics (magnetopause, cusp, and boundary layers)

\section{Introduction}

Determining the location of the open/closed field-line boundary (OCB) in the ionosphere, over a wide longitude sector, is of critical importance for many

Correspondence to: M. Pinnock

e-mail: M.Pinnock@bas.ac.uk studies. It is required in order to measure remotely the rate of reconnection at the magnetopause or in the magnetotail; to determine the size of the polar cap and hence the creation and destruction of open magnetic flux in the substorm cycle; to determine whether any phenomenon observed in the ionosphere is located on open or closed field lines, which usually has major implications for the physics involved. Precipitating particles provide one of the most direct ionospheric signatures of reconnection, whether it be through observation of the particles by satellite (e.g. Newell and Meng, 1991) or the auroral emissions triggered by the particles (e.g. Sandholt et al., 1998). However, timeof-flight effects in the presence of convecting plasma (i.e. the velocity filter signature described by Hill and Reiff, 1977) mean that an offset exists between the location of the OCB and that of the equatorward edge of the particle boundary. This has been illustrated and discussed in Lockwood (1998) for both magnetopause and magnetotail reconnection. Thus the particle signatures must be viewed as a "proxy" for the true location of the OCB.

A relationship between magnetospheric cusp particle precipitation into the ionosphere and HF radar backscatter from the ionospheric $\mathrm{F}$ region has been reported on by a number of workers (Baker et al., 1990, 1995; Rodger et al., 1995; Yeoman et al., 1997; Milan et al., 1999) and has been used as an alternative means of determining the OCB at noon (Baker et al., 1997; Pinnock et al., 1999). The equatorward edge of radar scatter showing large Doppler spectral widths has been shown to be coincident with the equatorward edge of the cusp particle precipitation (Baker et al., 1990, 1995) for a southward interplanetary magnetic field (IMF). Whilst observations have been presented which show low spectral width backscatter regions equatorward of the cusp (Pinnock et al., 1995), it is more common for the backscatter to start at the equatorward edge of the cusp. Milan et al. (1998) have shown that the cusp particle precipitation region forms a "hard" target for the radars, in the sense that the radar backscatter from it marks a true geophysical boundary and its location is 
relatively insensitive to HF propagation conditions. André et al. (1999) have identified the cause of the high Doppler spectral widths. They find that the intense Pc1 wave activity present in the cusp region produces the large Doppler spectral widths as a signal processing artifact. The SuperDARN radars (Greenwald et al., 1995) each provide a field of view encompassing $2-3 \mathrm{~h}$ of magnetic local time (MLT), giving a 2D view of the boundary which is not attainable by other techniques with the same spatial $(45 \mathrm{~km})$ and temporal resolution (120 s in normal mode).

The HF radar signature of the cusp ionosphere will also be offset from the true location of the OCB. This offset will be controlled by three factors: (1) the distance along the magnetic field line from the reconnection site to the ionosphere, (2) the field-aligned velocity of the injected ions; (3) the poleward flow component of the flux tube containing the injected ions. We assume that the cusp particle precipitation travels at the speed of the ions and not at the electron speed. This offset has previously only been considered in one dimension (e.g. along a line of meridian) and has been estimated to be $\sim 150 \mathrm{~km}$ (Rodger and Pinnock, 1997) near noon.

Rodger (2000) suggested that the longitudinal variation of the poleward flow component in the throat flow region would result in a characteristic bay-like feature, with the cusp radar backscatter displaced the greatest distance poleward where the poleward flow component maximises. Figure 1, taken from Rodger (2000) shows schematically this feature for two orientations of the IMF $B y$ component. The same considerations would apply to the cusp $630 \mathrm{~nm}$ auroral emission, however it would be difficult to observe such a feature with a single instrument because of its scale size. Pinnock et al. (1999), using conjugate HF radars showed data that were consistent with both hemispheres showing such a

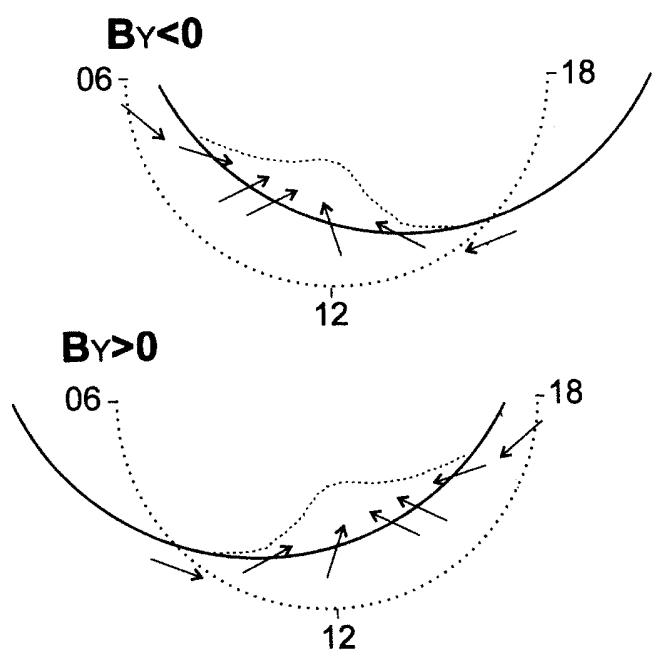

Fig. 1. The open/closed field line boundary (solid line) and the ionospheric footprint of the $630 \mathrm{~nm}$ auroral emission or the high Doppler spectral width regions as detected by an HF radar (broken line) between 06-18 magnetic local time. The arrows give the plasma flow direction, and the dotted line marks a constant magnetic latitude. The upper and lower patterns are for $B y<0$ and $B y>0$ in the Northern Hemisphere (Rodger, 2000) bay-like feature in the location of the cusp radar scatter. However, there is both spatial and temporal ambiguity in interpreting the data used in that study.

In this work, we present data from four adjacent SuperDARN radars. Our findings support the suggestion of Rodger (2000) in that a bay-like feature is found to exist in the cusp radar scatter. The results reaffirm the intimate link between radar scatter showing the characteristics defined in Baker et al. (1995) and the cusp particle precipitation and must be taken in to account when the radar scatter is used as a proxy for the open/ closed field line boundary (e.g. Baker et al., 1997; Pinnock et al., 1999). A method for producing more accurate estimates of the location of the OCB is described.

\section{Observations}

Data from the Stokkseyri (Iceland), Goose Bay (Labrador, Canada), Kapuskasing (Ontario, Canada) and Saskatoon (Saskatchewan, Canada) SuperDARN radars for the period 15 February, 1995, 1450-1530 UT are used in this study.

\subsection{Solar wind and IMF}

Figure 2 shows IMF and solar wind parameters from the Wind and IMP-8 spacecraft. Cross correlating the Wind and IMP-8 IMF data ( $B z$ and $B y$ components) gives a peak correlation (0.7) at a lag of $1920 \mathrm{~s}$ (32 min) between the two spacecraft.

In the IMP-8 data, from $\sim 1402$ UT until 1430 UT the IMF $B z$ component is northward and $B y$ is weakly negative. From 1430 UT onwards the IMF $B z$ component is close to $0 \mathrm{nT}$ apart from two epochs, 1442-1454 UT and 1500-1510 UT when periods of $B z$ southward $(\sim-3 \mathrm{nT})$ occur. In the same two periods the predominantly negative IMF $B y(\sim-4 \mathrm{nT})$ goes to $\sim 0 \mathrm{nT}$. The dynamic solar wind pressure shows very little variation throughout the study period, there is a single pulse at 1424 UT and some slight variability after 1512 UT. There is good agreement between the Wind and IMP-8 data series, allowing for the relative time delay estimation.

The delay from the spacecraft to the ionosphere has been evaluated by using the ionospheric plasma flow response to two near identical IMF events occurring at IMP-8 at 1447 and 1509 UT. When $B z$ goes negative and $B y$ goes to $\sim 0$ we would expect to observe almost purely poleward plasma flows in the ionospheric cusp. For the first event, the maximum positive excursion of IMF $B y$ is observed at Wind at 14:15:10 UT and at IMP-8 at 14:46:47 UT, and the ionospheric response (flow reconfigures to nearly poleward at noon) is seen at 14:55:06. This gives a delay of $1897 \mathrm{~s}(31 \mathrm{~min} 37 \mathrm{~s}$ ) between the two spacecraft, and a delay from Wind to the ionosphere of $2396 \mathrm{~s} \mathrm{(39} \mathrm{min} 56 \mathrm{~s}$ ) and from IMP-8 to the ionosphere of $499 \mathrm{~s}(8 \mathrm{~min} 19 \mathrm{~s})$. For the second event, the maximum positive excursion of IMF $B y$ is 

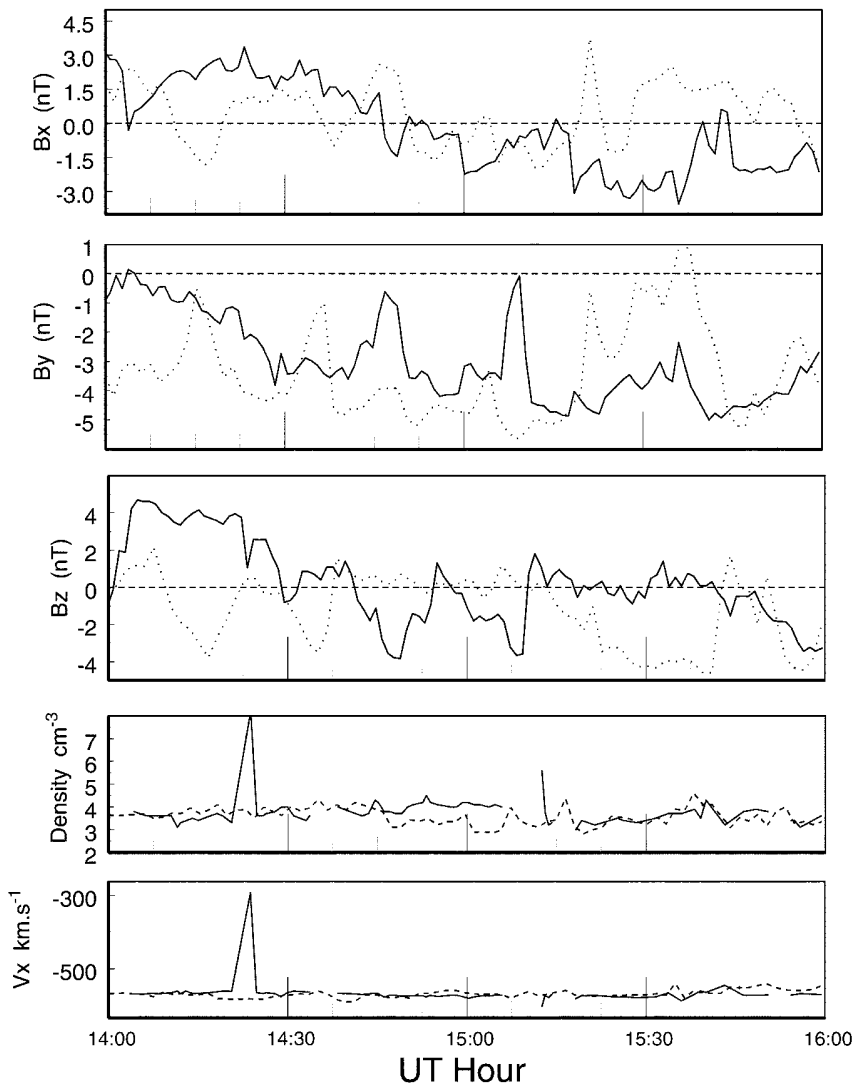

Fig. 2. Interplanetary Magnetic Field measured by the Wind (dashed lines) and IMP-8 (solid lines) spacecraft on 15 February, 1995. The top three panels show the IMF $B x, B y$ and $B z$ components in the GSM coordinate system. The last two panels show the solar wind plasma density and velocity in the $x$-plane. The position of the spacecraft in $\mathrm{GSM}$ at $1500 \mathrm{UT}$ is: Wind, $\mathrm{X}=197.37 R e, \mathrm{Y}=-35.36 R e, \mathrm{Z}=$ $-6.94 R e ; \mathrm{IMP}-8, \mathrm{X}=22.96 R e, \mathrm{Y}=-16.60 R e, \mathrm{Z}=-16.04 R e$

observed at Wind at 14:36:38 UT and at IMP-8 at 15:09:18 UT, and the ionospheric response is seen at 15:20:06. This gives a delay of $1960 \mathrm{~s}$ ( $32 \mathrm{~min} 40 \mathrm{~s}$ ) between the two spacecraft, and a delay from Wind to the ionosphere of $2608 \mathrm{~s} \mathrm{(43} \mathrm{min} 28 \mathrm{~s}$ ) and from IMP-8 to the ionosphere of $648 \mathrm{~s}(10 \mathrm{~min} 48 \mathrm{~s})$. [Note that between the two events the delay between the two spacecraft increases by $63 \mathrm{~s}$ but the total delay (to the ionosphere) increases by between $212 \mathrm{~s}$ (Wind) and $149 \mathrm{~s}$ (IMP-8)]. From this we take a mean delay from Wind to the ionosphere of $2502 \mathrm{~s}(41 \mathrm{~min} 42 \mathrm{~s})$ and for IMP-8, $574 \mathrm{~s}$ (9 $\mathrm{min} 34 \mathrm{~s})$ but note the degree of variability in the delay which is of the order of $\pm 60 \mathrm{~s}$ for the IMP-8 data.

\subsection{Radar data}

The SuperDARN radars were operating in a normal scanning mode, sweeping out all sixteen beams in a period of $100 \mathrm{~s}$. However, this period pre-dates the commencement of full SuperDARN operations and so the radars were not synchronised in the time at which they started their scans. The result is that the temporal resolution of the merged vectors sometimes degrades to
120 s. Strong scatter was observed by all the radars from 1450 to 1530 UT, which coincides with the IMF $B z$ component being mainly southward and small $B y$. This scatter allows maps of the Doppler spectral width and the convection pattern from 0900 to 1400 MLT to be produced. The scatter outside this period was not uniform across all the radars and thus limits the period of study.

2.2.1 Ionospheric plasma flow. Figure 3 shows a typical convection map produced from the radar data, taken from the radar scans around $1515 \mathrm{UT}$. The vectors have been produced by merging line-of-sight velocity data from the two radars in regions where the radar beams overlap. Line-of-sight velocities with measurement errors greater than $100 \mathrm{~ms}^{-1}$ have not been used in the analysis. The vectors show a well-defined throat flow region (flow rotating poleward and moving into the polar cap) which spans $\sim 3$ h of MLT, centred about 12 MLT. The width of the throat flow region varies little throughout the study period. Vectors provide patchy coverage of the sunward return flow region between $\sim 07$ MLT and 14 MLT.

To illustrate the response of the ionospheric plasma flow to the varying IMF conditions, Fig. 4 shows the average flow conditions at $\sim 13$ MLT in the polar cap, produced by averaging vectors along the $40^{\circ} \mathrm{E}$ meridian over the latitudinal range 78 to $81^{\circ} \mathrm{N}$ geomagnetic. For the prevailing IMF conditions ( $B y$ negative) the flow at this location is expected to be eastward and poleward, as is observed for most of the time. The two periods of enhanced IMF $B z$ negative and $B y \sim 0$ produce similar responses (marked by the arrows), although the later event is much more pronounced. The flow is enhanced in magnitude and rotates to a more poleward (northward) flow. These were the two flow responses used to estimate the delay from the solar wind monitors to the ionosphere. However, note that a similar flow rotation occurs at 1544 UT, during a period of apparently steady IMF clock angle, as measured at IMP-8.

2.2.2 Radar backscatter characteristics. We next examine the location of the radar backscatter showing high Doppler spectral width, and examine its relationship to the convection pattern.

Figure $3 \mathrm{~b}$ shows the Doppler spectral widths from the individual radars with the vectors overlaid from the time interval around 1515 UT. Large Doppler spectral widths $(>250 \mathrm{~m} / \mathrm{s})$ dominate the scatter, but there is a poleward excursion of the large spectral widths centred around the throat flow region (1120-1220 MLT). At this particular time, the "bay" formed by the high spectral widths is filled in with ionospheric scatter showing low spectral widths. This is not always the case, often the scatter forming the equatorward edge of the received echoes has large spectral widths. In Fig. 3B, regions of overlapping radar field-of-view have only scatter from one of the radars plotted. Time series of individual radar's spectral width data have been examined to ensure that Fig. 3B is representative of all the data, i.e. different radars do not differ 
(A)

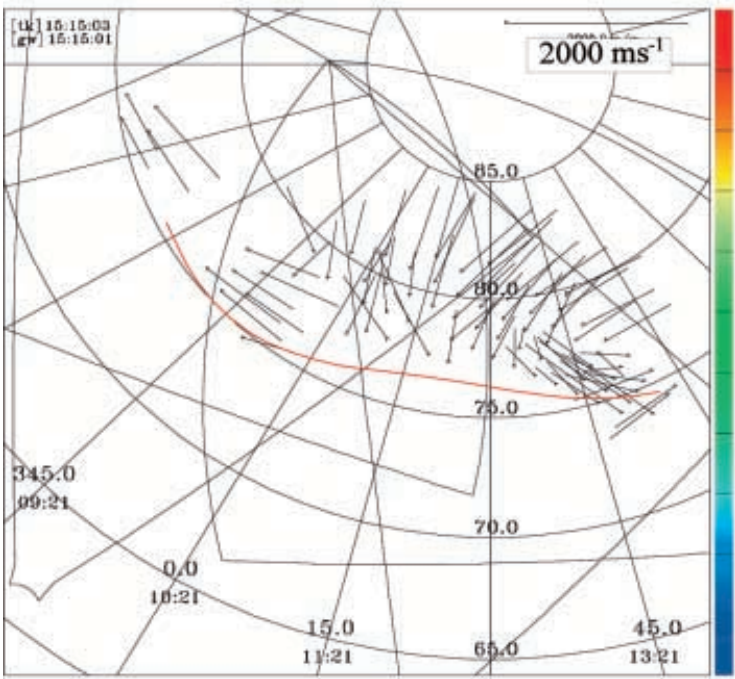

475

425

375

325

275

225

175 की

125

75

25

Fig. 3. A A polar projection in the AACGM coordinate system showing the flow vectors derived from the two radar pairs for the interval around 15:15 UT. The triangle marks the location at which the measurement was made, the line shows the direction and the length

markedly in where they determine the high Doppler spectral width region to be. Only data outside the convection reversal region (in the afternoon cell) have been compared in this manner. In the vicinity of a convection reversal, André et al. (2000) have shown that more zonally pointing beams (e.g. those from the Stokkseyri radar) will produce large spectral widths simply from the inhomogeneity of the velocity field within the radar sampling cell.

The equatorward boundary of the scatter showing high spectral widths has been determined by thresholding the data so that scatter with a Doppler spectral
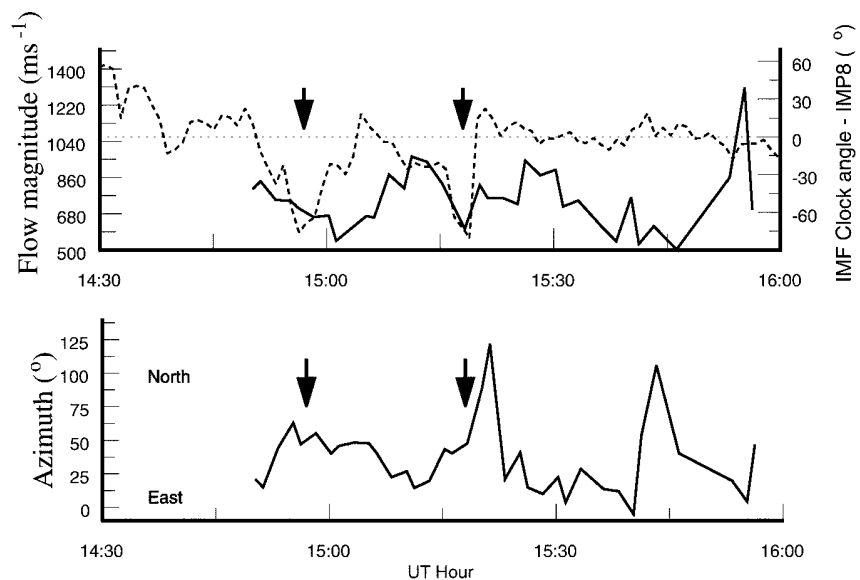

Fig. 4. The average ionospheric flow conditions in the polar cap at $40^{\circ} \mathrm{E}(13 \mathrm{MLT})$ and latitude range $78-81^{\circ} \mathrm{N}$ geomagnetic during the period of study. The top panel shows the flow magnitude (left hand axis, solid line) and the IMF clock angle (right hand axis, dashed line) measured by IMP-8, plotted with a delay of 574 seconds. For the latter, $-90^{\circ}$ is a southward IMF, whilst $0^{\circ}$ is a westward IMF. The arrows identify the IMF events referred to in the text. The lower panel shows the azimuth of the flow
(B)

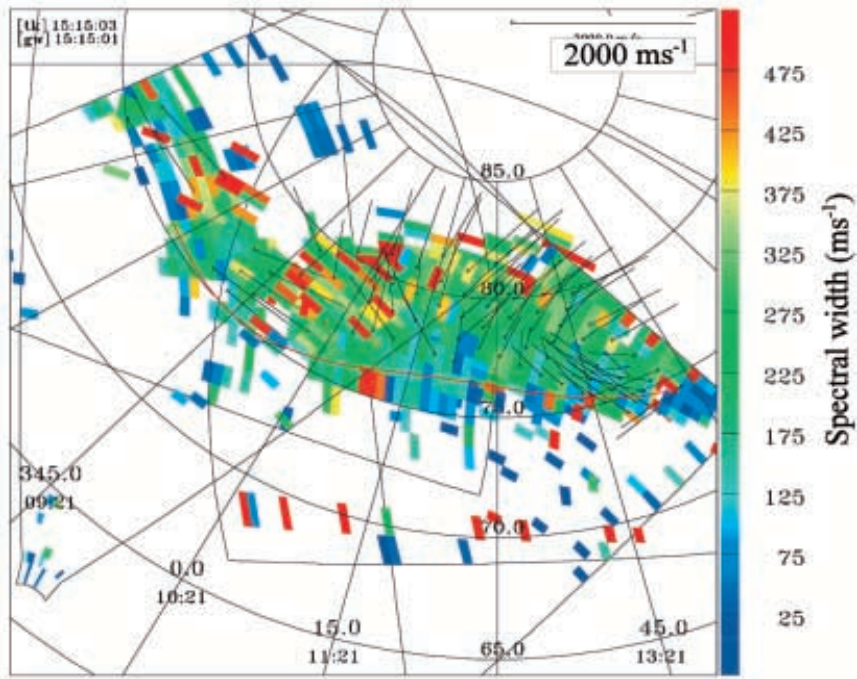

the magnitude of the flow. $\mathbf{B}$ is identical to $\mathbf{A}$, except that the Doppler spectral widths have been over laid on the vectors. The red line shows the smoothed location of the high Doppler spectral width region (see text) and the blue lines show the fields-of-view of the radars

width $<150 \mathrm{~ms}^{-1}$ is excluded. The series of latitude/ longitude values describing the boundary has then been smoothed to give interpolated values that can be matched to the longitude at which velocity vectors existed. The resulting boundary for 1515 UT is shown in Fig. 3A, B (red line). This procedure has been repeated for all radar scan periods and Fig. 5 shows the boundary (solid line) for radar scans separated at approximately 5 min intervals. The dashed lines in Fig. 5 show the poleward component to the plasma flow (Vpp), determined from the radar velocity vector nearest to the boundary at a given longitude. From Fig. 3 it can be seen that the velocity vectors are not always coincident with the equatorward edge of the scatter, and in calculating Vpp we have taken the nearest vector.

Figure 5 shows the presence of a bay (poleward displacement) in the scatter with high spectral widths, centred at about $20^{\circ} \mathrm{E}$ (1140 MLT). It shows considerable variability in depth, varying from about $3^{\circ}$ (15:06:21 UT) to $1^{\circ}(15: 11: 19 \mathrm{UT})$. Its width is typically of the order of $40^{\circ}$ of longitude or nearly $3 \mathrm{~h}$ of MLT, which is the same as the width of the throat flow region.

The presence of this bay is consistent with the previous results of Pinnock et al. (1999), who used the Doppler spectral width characteristics from HF radar data to identify the orientation of the cusp with longitude in both hemispheres. Converting the observations in this study to the angular measure used in the earlier paper, we find that the angle of tilt (with respect to a line of constant magnetic latitude) is typically $25^{\circ}$ and has a maximum of $39^{\circ}\left(15: 06: 21 \mathrm{UT}\right.$, between $1^{\circ}$ and $16^{\circ} \mathrm{E}$ longitude). These angles are very similar to those reported in the previous paper for the Northern Hemisphere radar but larger than the Southern Hemisphere results. Baker et al. (1997) performed a similar analysis and found comparable tilts in the orientation of the cusp 


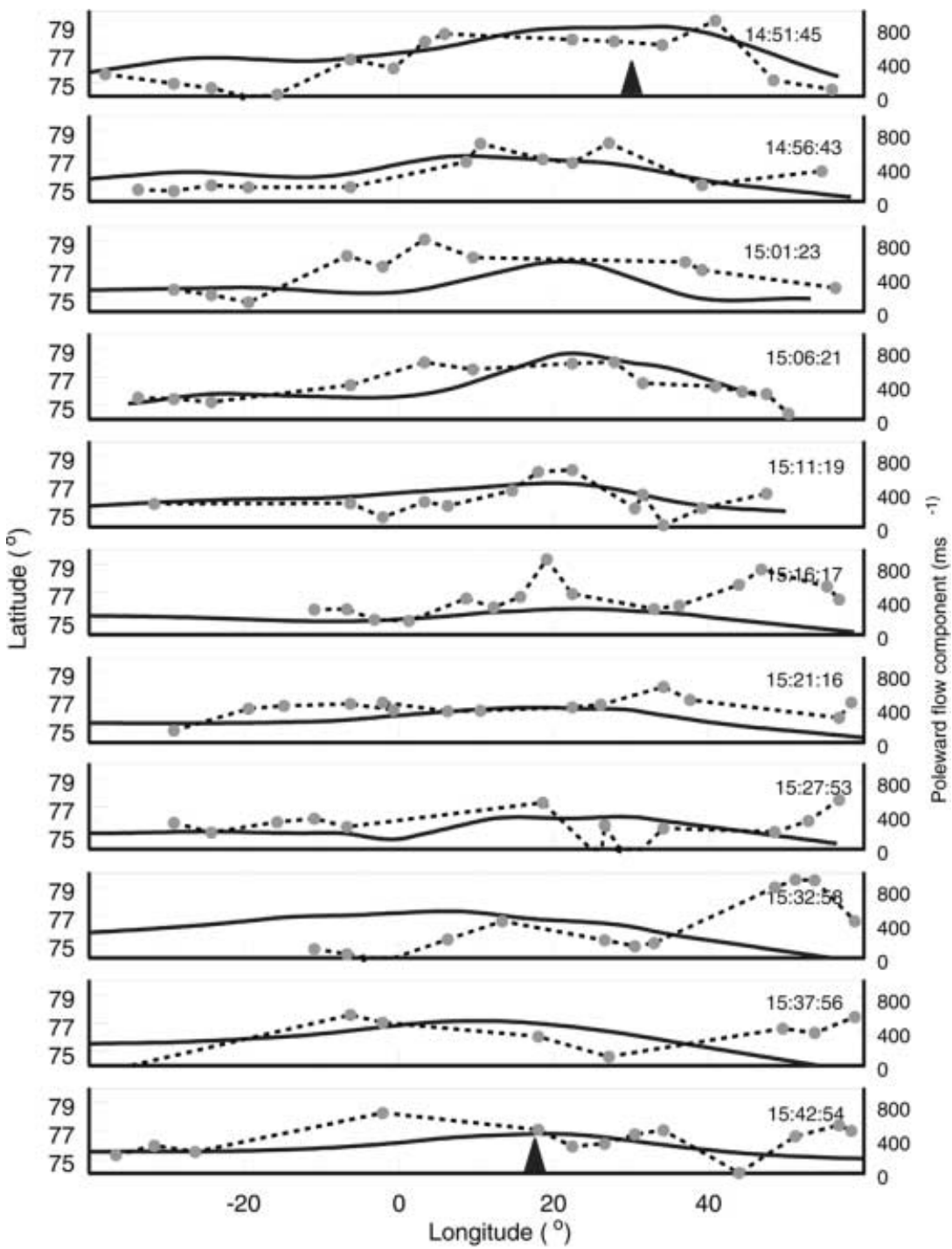

Fig. 5. Each panel shows the smoothed location of the equatorward edge of the spectral width boundary (solid line) against latitude (left hand $y$ axis) and longitude $(x$-axis). The dashed line (with circles at each data point) shows the magnitude of the poleward flow component (right hand axis) in the ionosphere. The arrows in the top and bottom panel mark the location of magnetic local noon, the time of each radar scan is given in the top right of the panels but their results did not completely describe a bay, perhaps because their data set did not span the full throat region.

The curves showing the poleward velocity component $(\mathrm{Vpp})$ have much greater variability than is seen in the boundary data. They usually show the largest Vpp occurs in the throat flow region (between $0^{\circ}$ and $30^{\circ}$ longitude) and sometimes have a form similar to the boundary data (e.g. 14:51, 14:56, 1511 UT). But there are periods when there appears to be little similarity between the boundary data and the peak in the poleward flow component, e.g. 15:32:58 UT. We have several reasons for suspecting that the poleward velocity component is not always well matched with the boundary data. The data do not always allow measurement of the poleward flow component exactly at the location of the spectral width boundary because vectors are not always present at that location. Also, because there is a significant zonal flow component, it may be that velocity vectors at a longitude east or west of the particular longitude of the boundary would be a better choice than simply taking the nearest vector.
2.2.3 Deriving time-of-flight of cusp ions from the radar data. Because of the variability of the poleward flow component we have attempted to test for a possible relationship between the poleward displacement of the scatter with high Doppler spectral width and the poleward flow component by averaging the data for each scan in the following manner. A proxy for the open/closed field line boundary is taken to be the lowest latitude $(\Lambda \circ c)$ of the radar backscatter with Doppler spectral widths $>150 \mathrm{~ms}^{-1}$ in the morning convection cell adjacent to the throat flow region. It is also assumed that the OCB is close to being aligned along a line of constant magnetic latitude, which is $\Lambda$ oc, in the noon sector. The displacement of the radar backscatter from this boundary (D) in the longitude range $0-40^{\circ}$ East is then scaled. We discuss later the reasons for limiting the data selection to this longitude range and the validity of the technique for determining $\Lambda$ oc. The calculation, $\mathrm{D} / \mathrm{Vpp}$, should then give the time of flight of the cusp ions.

Figure 6 shows the results of this analysis, the circles giving the average time of flight determined from each 


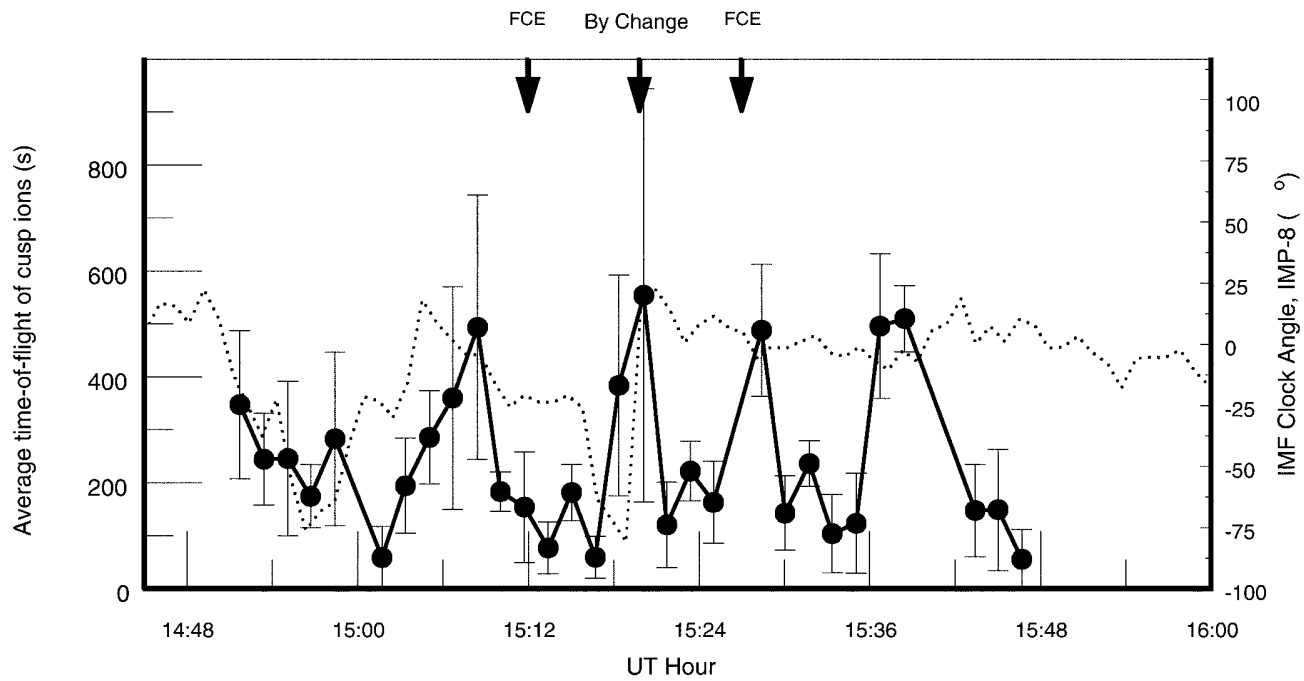

Fig. 6. The average time-offlight of cusp ions, computed for each radar scan time (see text), are plotted as solid circles. The standard deviation of the average is plotted as error bars $( \pm)$. The IMF clock angle measured by the IMP-8 satellite, delayed by $574 \mathrm{~s}$, is plotted by the dotted line. The three arrows mark the times of flow transients in the ionosphere (discussed in the text) radar scan period, the error bars \pm the standard deviation about this average. Also plotted in Fig. 6 is the delayed IMF clock angle from the IMP-8 spacecraft. This plot suggests that the time of flight derived by this method is typically between 100 and $200 \mathrm{~s}$. The most extreme values (e.g. $550 \mathrm{~s}$ ) have very large standard deviations. The three arrows in Fig. 6 mark the time of flow transients observed in the data that are the subject of a separate paper. The two arrows marked "FCE" are at the times that flow channel events, possible flux transfer event (FTE) signatures (Pinnock et al., 1993), are observed whilst the third arrow is at the time that the IMF changed, returning back to a $B y$ dominated regime. It should be noted that three out of the four largest values for time-of-flight of the cusp ions occur during these transient events.

If we assume that the magnetosheath ions have been injected at the subsolar point (possibly only valid for the periods when negative $B z$ dominated the IMF) and that they transit a field-aligned distance of $\sim 13 R e$ to reach the ionosphere (obtained from the Tsyganenko 96 magnetospheric field model (Tsyganenko, 1995)) then the cusp ion transit times derived above correspond to ions with energies ranging between $3.6 \mathrm{keV}(100 \mathrm{~s})$ and $900 \mathrm{eV}(200 \mathrm{~s})$. If the field-aligned distance is less, for example $10 R e$ as suggested by Newell et al. (1995), then the corresponding energy range would be $2.1 \mathrm{keV}$ (100 s) to $530 \mathrm{eV}(200 \mathrm{~s})$.

The ion energies derived compare favourably with those observed in the low-altitude cusp by DMSP satellite (see e.g. Newell and Meng, 1988), the higher energies being close to those often observed at the equatorward edge of the cusp particle precipitation (Newell and Meng, 1991, see their Fig. 2). This is consistent with the equatorward edge of the high spectral width region mapping to the equatorward edge of the cusp particle precipitation (Baker et al., 1990, 1995) and the sharp increase in Pcl wave activity associated with the equatorward edge of the cusp particle precipitation (e.g. Erlandson and Anderson, 1996) being the cause of the large Doppler spectral widths (André et al., 1999).

\section{Discussion}

The analysis presented in this paper shows the following.

a. The location of HF radar backscatter showing characteristics of the cusp (Baker et al., 1995) shows a poleward bay around the noon region. This feature was predicted by Rodger (2000), and is a consequence of the time-of-flight of injected cusp ions and the longitudinal variation of the poleward plasma convection velocity near noon.

b. It has been possible, making assumptions about the true location of the OCB and the likely distance travelled by the ions from the reconnection site, to derive an estimate of the time of flight of the injected cusp ions and hence the average ion energies. The energies are found to be typical of those found at the equatorward edge of the cusp particle precipitation.

It should be stressed that we are not proposing that the technique for deriving the time-of-flight of cusp ions be used to infer properties of the reconnection X-line on the magnetopause, which can be done with greater accuracy using satellite particle data (e.g. Lockwood et al., 1995). Rather the technique has been employed to provide further evidence for the link between HF radar backscatter characteristics and cusp particle precipitation (Baker et al., 1995) and to understand the morphology of the high spectral width boundary around noon.

We have made several assumptions in this work, all of which may contribute errors to our estimate of the time of flight of the cusp ions. First, we have used a quasi-steady-state model for the transit of the cusp particles from the reconnection site to the ionosphere, but it is noted that the largest errors on the average time-of-flight from our analysis occurred, in three out of four cases, during flow transients observed in the radar data. We have also assumed perfect mapping between the magnetosphere and ionosphere of electric fields. In particular, the assumption is made that the poleward velocity component at any particular instant is to be associated with the cusp ions arriving in the ionosphere at the same time. This is certainly an area where there is incomplete understanding. We have also not taken any 
account of the dynamics of the OCB associated with the reconnection process, such as have been suggested by Cowley and Lockwood (1992). Their model shows that the addition of new flux in the reconnection process leads to an equatorward motion of the OCB in the noon sector, followed by subsequent relaxation poleward as the flux is distributed in to the polar cap. However, the maximum magnitude of the equatorward motion of the OCB observed by Sandholt et al. (1998) was $\sim 50 \mathrm{~km}$. Compared with the magnitude of the bay reported in this paper $(111-333 \mathrm{~km})$ this is a second order effect.

It should also be noted that the poleward velocity component in the ionosphere may be influenced by processes internal to the ionosphere (e.g. conductivity gradients) and other magnetospheric processes (e.g. response to magnetosheath pressure variations). However, we would expect our averaging process to identify the dominant forcing, i.e. reconnection.

We also assume that the lowest latitude of large spectral widths in the morning cell is the OCB latitude in the noon region. It is only the consistency of our results (i.e. we compute realistic average ion energies for the equatorward edge of the cusp particle precipitation) which validate this assumption, no satellite data being available for this study period. We have used the morning cell, rather than the afternoon cell, because the radar data from this region is taken from beam directions that are close to meridional. The Baker et al. (1995) studies were done with meridional pointing beams. As noted earlier, André et al. (2000) have shown that a radar with more zonally aligned beams, when sampling a steady-state convection pattern in the vicinity of the convection reversal boundary, will produce large Doppler spectral widths (>200 m/s). Data from the afternoon cell in this study comes from the Stokkseyri radar, whose beams are close to zonal in direction and will thus be subject to this effect.

A more complete understanding of the morphology of the HF radar high spectral width boundary around the noon sector allows a more accurate estimate of the open/closed field line boundary to be made. In HF radar studies (Baker et al., 1997; Pinnock et al., 1999) which measured the reconnection electric field $\left(\mathrm{E}_{\mathrm{rec}}\right)$, it was assumed that the critical measurement was plasma flow perpendicular to the equatorward edge of the high spectral width region (which was assumed to be the OCB). Here we show that the supposedly tilted OCB reported in these studies is produced as a result of the combination of time-of-flight of cusp ions and convection, i.e. the true orientation of the OCB was not being observed. Taking account of the typical tilt angles reported by Baker et al. (1997) and Pinnock et al. (1999) for the Northern Hemisphere, we estimate that the maximum error in their $\mathrm{E}_{\text {rec }}$ values would be $\sim 15 \%$.

Future studies using the SuperDARN radars to determine the reconnection electric field should apply a correction to determine a more accurate location of the OCB. Two methods could be used. In this work we have used the lowest latitude of the large Doppler spectral widths in the morning or afternoon convection cells, immediately adjacent to the throat flow region (in meridional pointing radar beams) to provide a constant latitude for the OCB across the noon sector. The consistency of our results (i.e. we achieve plausible ion energies) demonstrate that this is a valid approach. Alternatively, one could use the poleward flow component measured in the ionosphere by the radar. Combined with an assumed average ion energy of, say, $1 \mathrm{keV}$ (for zero degree pitch angle ions) and a likely distance travelled by the ions it would then be possible to estimate the location of the OCB. This second method could also be employed with other techniques (precipitating particles or auroral emissions) providing that ionospheric plasma flow information is available.

Finally, our results make it possible to understand one unexplained aspect of the study by Pinnock et al. (1999). In that paper, the presence of the noon bay in the Doppler spectral width values was demonstrated in both hemispheres, but the Northern Hemisphere had a much deeper bay (greater poleward displacement) than the Southern Hemisphere (see Pinnock et al., 1999, Fig. 3A, B). Also, larger reconnection electric field values were measured in the Northern Hemisphere, shown to be consistent with the higher latitude at which the cusp was found in that hemisphere. From the present study, we can see that larger reconnection electric fields would be expected to produce a deeper bay, and hence give larger tilt angles.

\section{Conclusions}

It has been shown that the longitudinal variation of the poleward flow component in the throat flow region results in a characteristic bay-like feature of the cusp particle precipitation, as demonstrated using HF radar Doppler spectral width data as a proxy. This feature must be taken into account when any ionospheric proxy for the open/closed field line boundary (OCB) is used (e.g. precipitating particle data from satellites and cusp auroral emissions). A method for providing an improved estimate of the latitude of the OCB and its variation with longitude, using the poleward flow component measured in the ionosphere and certain assumptions regarding the characteristics of the precipitating cusp ions, has been described.

Acknowledgements. Support for the SuperDARN radars used in this study has been provided by agencies in Canada, France and the USA. The Goose Bay and Kapuskasing radars are operated under support from NSF Grant ATM-9812078 and NASA Grant NAG5-8361, respectively. The Wind and IMP-8 satellite data were provided by the NASA/GSFC CDAWeb and we thank Drs. R. Lepping, A. Lazarus and K. Ogilivie for making them available.

Topical Editor G. Chanteur thanks N. Nishitani and M. Kessel for their help in evaluating this paper.

\section{References}

André, R., M. Pinnock, and A. S. Rodger, On the SuperDARN autocorrelation function observed in the ionospheric cusp, Geophys. Res. Lett., 26, 3353, 1999. 
André, R., M. Pinnock, J.-P. Villain, and C. Hanuise, On the factors conditioning the Doppler spectral width determined from SuperDARN HF radars, Int. J. Geomagn. Aeron., in press, 2000.

Baker, K. B., R. A. Greenwald, J. M. Ruohoniemi, J. R. Dudeney, M. Pinnock, P. T. Newell, M. E. Greenspan, and C.-I. Meng, Simultaneous HF-radar and DMSP observations of the cusp, Geophys. Res. Lett., 17, 1869, 1990.

Baker, K. B., J. R. Dudeney, R. A. Greenwald, M. Pinnock, P. T. Newell, A. S. Rodger, N. Mattin, and C.-I. Meng, HF radar signatures of the cusp and low-latitude boundary layer, J. Geophys. Res., 100, 7671, 1995.

Baker, K. B., A. S. Rodger, and G. Lu, HF-Radar observations of the rate of magnetic merging: a GEM boundary layer campaign study, J. Geophys. Res., 102, 9603, 1997.

Cowley, S. W. H., and M. Lockwood, Excitation and decay of solar-wind driven flows in the magnetosphere-ionosphere system, Ann. Geophysicae, 10, 103, 1992.

Erlandson, R. E., and B. J. Anderson, Pcl waves in the ionosphere: a statistical study, J. Geophys. Res., 101, 7843, 1996.

Greenwald, R. A., K. B. Baker, J. R. Dudeney, M. Pinnock, T. B. Jones, E. C. Thomas, J.-P. Villain, J.-C. Cerisier, C. Senior, C. Hanuise, R. D. Hunsucker, G. Sofko, J. Koehler, E. Nielsen, R. Pellinen, A. D. M. Walker, N. Sato, and H. Yamagishi, DARN/ SuperDARN: a global view of the dynamics of high latitude convection, Space Sci. Rev., 71, 761, 1995.

Hill, T. W., and P. H. Reiff, Evidence of magnetospheric cusp proton acceleration by magnetic merging at the dayside magnetopause, J. Geophys. Res., 82, 3623, 1977.

Lockwood, M., Identifying the open-closed field line boundary, Polar cap boundary phenomena, Eds J. Moen et al., Kluwer Academic Publishers, Dordrecht 73, 1998.

Lockwood, M., C. J. Davis, M. F. Smith, T. G. Onsager, and W. F. Denig, Location and characteristics of the reconnection X-line deduced from low-altitude satellite and ground-based observations 2. Defense Meteorological Satellite Program and European Incoherent-scatter data, J. Geophys. Res., 100, 21803, 1995.

Milan, S. E., T. K. Yeoman, and M. Lester, The dayside auroral zone as a hard target for coherent HF radars, Geophys. Res. Lett., 25, 3717, 1998.

Milan, S. E., M. Lester, S. W. H. Cowley, J. Moen, P. E. Sandholt, and C. J. Owen, Meridian-scanning photometer, coherent HF radar, and magnetometer observations of the cusp: a case study, Ann. Geophysicae, 17, 159, 1999.

Newell, P. T., and C.-I. Meng, The cusp and cleft/boundary layer: low-altitude identification and statistical local time variation, J. Geophys. Res., 93, 14 549, 1988.

Newell, P. T., and C.-I. Meng, Ion acceleration at the equatorward edge of the cusp: low-altitude observations of patchy merging, Geophys. Res. Lett., 18, 1829, 1991.

Newell, P. T., D. G. Sibeck, and C.-I. Meng, Penetration of the interplanetary magnetic field $B y$ and magnetosheath plasma into the magnetosphere: implications for the predominant magnetopause merging site, J. Geophys. Res., 100, 235, 1995.

Pinnock, M., A. S. Rodger, J. R. Dudeney, K. B. Baker, P.T., Newell, R. A. Greenwald, M. E. Greenspan, Observation of an enhanced convection channel in the cusp ionosphere, J. Geophys. Res., 98, 3767, 1993.

Pinnock, M., A. S. Rodger, J. R. Dudeney, F. Rich, and K. B. Baker, High spatial and temporal resolution observations of the ionospheric cusp, Ann. Geophysicae, 13, 919, 1995.

Pinnock M., A. S. Rodger, K. B. Baker, G. Lu, and M. Hairston, Conjugate HF-Radar observations of the rate of magnetic merging: a GEM boundary layer campaign, Ann. Geophysicae, 17, 443, 1999.

Rodger, A. S., S. B. Mende, T. J. Rosenberg, and K. B. Baker, Simultaneous optical and HF radar observations of the ionospheric cusp, Geophys. Res. Lett., 22, 2045, 1995.

Rodger, A. S., and M. Pinnock, The ionospheric response to flux transfer events - the first few minutes, Ann. Geophysicae, 15, 686, 1997.

Rodger, A. S., Ground-based imaging of magnetospheric boundaries, Adv. Space Res., 25, (7/8) 1461, 2000.

Sandholt, P. E., C. J. Farrugia, M. Øieroset, P. Stauning, and W. F. Denig, Auroral activity associated with unsteady magnetospheric erosion: observations on December 19, 1990, J. Geophys. Res., 103, 2309, 1998.

Tsyganenko, N. A., Modeling the Earth's magnetospheric magnetic field confined within a realistic magnetopause, J. Geophys. Res., 96, $15789,1995$.

Yeoman, T. K., M. Lester, S.W.H. Cowley, S.E. Milan, J. Moen, and P. E. Sandholt, Simultaneous observations of the cusp in optical, DMSP and HF radar data, Geophys. Res. Letts., 24, 2251, 1997. 